\title{
Study on the Performance of Beidou High-precision Reference Station Network in Beibu Gulf of Guangxi
}

\author{
Xinying Zhong,Yifei Yang,Conglin Zhou
}

Geomatics Center of Guangxi

\begin{abstract}
KEY WORDS: Beibu Gulf of Guangxi in China; Beidou system; Navigation and Positioning; time availability; internal/external accordant accuracy
\end{abstract}

\begin{abstract}
:
Beidou high-precision reference station network in Beibu Gulf of Guangxi consists of five parts, namely Beidou reference stations, the data processing system, the operation and service platform, the data broadcast system and user terminals. It is an important infrastructure for the construction of the China-ASEAN Information Harbor. Since its operation, the system has contributed significantly to the industrial development in Guangxi and the mass application of Beidou. This paper focuses on the operation of Beidou high-precision reference station network in Beibu Gulf of Guangxi from the perspectives of performance, navigation and positioning accuracy, application experience, etc. Experimental results demonstrated that: in the area of Beibu Gulf of Guangxi, the application of Beidou Navigation Satellite System (BDS) has significantly increased the number of satellites observed and enhanced the spatial accessibility of the system. The percentage of fixed solutions in the spatial accessibility test of the system was about $87.3 \%$; the network-wide time availability within the effective coverage of the system was $92.7 \%$; the internal accordant accuracy of points in Beibu Gulf BDS was 37.7\% and 33.3\% higher than the dual constellation system (GPS+GLONASS) in the horizontal and the vertical directions respectively, and the average external accordant accuracy was $20.60 \%$ higher than the dual constellation system in the horizontal direction (equivalent in the vertical direction). This paper objective reflected the present construction and utilization situation of Beidou high-precision reference station network in Beibu Gulf of Guangxi, which would be of great significance to the construction and development of the Beidou system.
\end{abstract}

\section{General Instructions}

Satellite navigation and positioning system is one of the most convenient ways to access information about spatial and geographic locations today. Commonly used systems include the global positioning system of the United States (GPS), GLONASS satellite navigation system of Russia (GLONASS), Beidou Navigation Satellite System of China (BDS) and Galileo Satellite Navigation System of EU (GALILEO). Among them, BDS is the third largest global satellite navigation and communication system independently developed by China. Currently, BDS has launched 31 satellites. As planned, BDS was to provide basic services to countries along and neighboring the "Belt and Road" by 2018 , and would complete the network with 35 satellites launched by 2020 and thereby serve users around the world[1].

Beidou high-precision reference station network was an important part of BDS high-precision navigation and positioning services. The system employed Beidou/ GNSS highprecision receiver and broadcast correction information of satellite positioning errors via mobile communication, digital broadcasting and other measures, thus enhancing the positioning accuracy of the original satellite navigation system and providing real-time high-precision navigation services at 1$2 \mathrm{~m}$, decimeter and centimeter level in the coverage[2].

Many scholars have conducted in-depth research of highprecision reference station networks of satellite navigation and positioning, as well as practices in China and different places around the world. Construction of Beidou high-precision reference station network agreed with the orientation of national policy and the requirements of security strategies, met the needs of industrialization of Beidou System and of the building of high-precision independent surveying and mapping reference. Meanwhile, the dynamic, three-dimensional and geocentric reference frame established on top of the high-precision reference station network met the needs of national geographic condition monitoring for information about the change of location of various elements, and could provide high-precision characteristics of plate motion, etc.[3] The building of Beidou high-precision reference station network should conform with the requirements of local economic and social development, prioritize the achievement of cross-industry and trans-regional information sharing, and actively develop applications of Beidou high-precision reference station network in geographic information, precision agriculture, modern weather forecasting, geological hazard monitoring, deformation monitoring and other fields[4]. With respect to system application, Beidou high-precision reference station network could achieve an equivalent positioning accuracy with GPS, while satisfying the needs of high-precision positioning with its accessibility[5].

\section{Performance of Beidou High-precision Reference Station Network in Beibu Gulf of Guangxi}

\subsection{Introduction to Beidou High-precision Reference Station Network in Beibu Gulf of Guangxi}

Beidou High-precision Reference Station Network in Beibu Gulf of Guangxi (hereinafter referred to as Beibu Gulf System) has completed the construction of 19 continuously operating reference stations (CORS) at provincial level in the area of Beibu Gulf as well as the upgrading of the triple constellation data processing platform of the data control center, connected with 7 national CORS to form 26 Beidou highprecision reference networks, thereby realizing the triple constellation high-precision navigation and positioning of Beidou compatible with GPS of America and GLONASS of Russia. Its performance and precision indicators were all equivalent or superior to the level of the current dual constellation high-precision reference station network, with 
which it provided high-precision positioning services at submeter, centimeter and post-processing millimeter level in Beibu Gulf to meet the needs of different positioning accuracies. Distribution of reference stations of Beibu Gulf System is as shown in Figure 1.

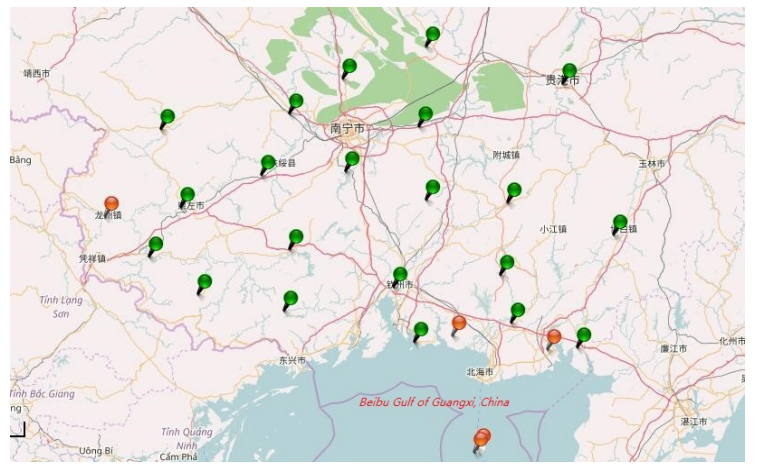

Figure 1. Distribution of Reference Stations of Beidou Highprecision Reference Station Network in Beibu Gulf of Guangxi

\subsection{Analysis of the Time Availability of the System}

The time availability of the system was tested by the $24 \mathrm{~h}$ continuous observation with equipment from the mainstream brand RTK of 2 testing points located inside and outside Beibu Gulf System respectively at different distances; taking continuous records of the original positioning results at the sampling rate of $1 \mathrm{~s}$, and working out the proportion of fixed solutions (effective epochs) to the total amount of data collected

4 testing points ( 2 outside and 2 inside the coverage of Beibu Gulf System) were RTK1 (37km outside), RTK3 (14km outside), RTK5 (inside) and RTK7 (inside). Points selected should be located near reference stations in good working conditions, be of good RTK observation conditions and meet the requirements of static accuracy test. Results of the statistical analysis of effective epochs in the time availability test of Beibu Gulf System are as shown in Figure 2.

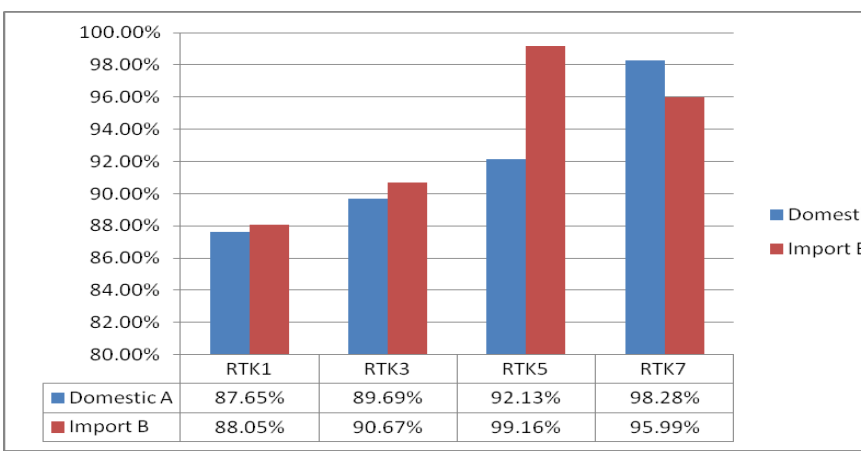

Figure 2. Statistics of Effective Epochs in the Test of System Time Availability
Table 1.Effective Epochs in the Test of System Time Availability

\begin{tabular}{|c|c|c|c|c|c|}
\hline \multirow{2}{*}{$\begin{array}{c}\text { Serial } \\
\text { number }\end{array}$} & RTK & \multicolumn{2}{|c|}{ Outside } & \multicolumn{2}{c|}{ inside } \\
\cline { 3 - 6 } & equipment & $\begin{array}{c}\text { RTK1 } \\
(\%)\end{array}$ & $\begin{array}{c}\text { RTK3 } \\
(\%)\end{array}$ & $\begin{array}{c}\text { RTK5 } \\
(\%)\end{array}$ & $\begin{array}{c}\text { RTK7 } \\
(\%)\end{array}$ \\
\hline 1 & $\begin{array}{c}\text { Domestic } \\
\text { A }\end{array}$ & 87.65 & 89.69 & 92.13 & 98.28 \\
\hline 2 & Import B & 88.05 & 90.67 & 99.16 & 95.99 \\
\hline 3 & Average & \multicolumn{2}{|c|}{89.52} & 96.39 \\
\hline 4 & $\begin{array}{c}\text { Average } \\
\text { (All) }\end{array}$ & \multicolumn{3}{|c}{92.70} \\
\hline
\end{tabular}

According to the statistical results in Table 1 and Figure 1, the average effective time availability outside the system network was $89.52 \%$ when using Beidou High-precision Reference Station Network in the area of Beibu Gulf in Guangxi for satellite navigation and positioning, $96.39 \%$ inside the system network, and $92.7 \%$ network-wide.

As demonstrated by the research, the average effective time availability of the dual constellation navigation system (GPS+GLONASS) in Nanning, Guangxi reached 91.7\%[2]. Comparatively speaking, after joining the Beidou constellation, the network-wide average effective time availability of Beibu Gulf System increased by $1 \%$.

\subsection{Analysis of the Spatial Accessibility of the System}

System spatial accessibility referred to the area in which users could obtain fixed network RTK solutions in real time. Spatial accessibility was tested by car-mounted RTK. The spatial coverage of the system could be roughly painted out based on the trajectories of the car-mounted test.

The test employed RTK from a domestic brand A and RTK from a foreign brand $\mathrm{B}$, which were connected to the data control system simultaneously; the sampling rate was set as $1 \mathrm{~s}$, the driving speed $40 \sim 60 \mathrm{~km} / \mathrm{h}$ and the operating mode of the receiver real-time RTK; coordinate results of RTK point solutions were recorded with the handbook and the range of RTK fixed solutions was obtained to determine the effective coverage of the system. After the test drive, RTK data recorded in real time were collected. The critical distance of RTK fixed solutions should be the coverage of the system. Statistics of the spatial accessibility test were shown in Figure 3 and Table 2.

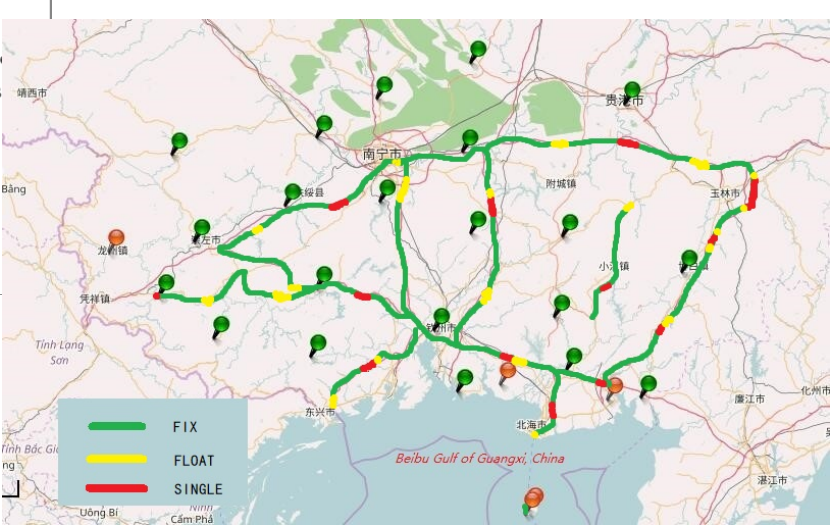

Figure 3. Results of the Test of System Spatial Accessibility 
Table 2. Statistics of the Test of Spatial Accessibility

\begin{tabular}{|c|c|c|}
\hline System & Terminal equipment & $\begin{array}{c}\text { percentage of } \\
\text { Fixed poionts }\end{array}$ \\
\hline $\begin{array}{c}\text { Beibu Gulf of } \\
\text { Guangxi system }\end{array}$ & Domestic A & $85.6 \%$ \\
\cline { 2 - 3 } & Import B & $89.0 \%$ \\
\hline \multicolumn{2}{|c|}{ Average } & $87.3 \%$ \\
\hline
\end{tabular}

From the statistical results in Table 2 and Figure 2, it was learned that the average spatial accessibility of the system was 87.3\% when using Beidou High-precision Reference Station Network in the area of Beibu Gulf in Guangxi for highprecision satellite navigation and positioning, which contained such factors that may hamper the system from obtaining fixed solutions as affected network RTK communication due to the driving speed, equipment and other objective factors in the test, satellite loss-of-lock due to zenith blocking, etc.

\subsection{Network RTK Positioning Accuracy}

Within the service coverage of Beibu Gulf System, 7 known control points evenly distributed were selected as testing points, spreading across mountains, plains, and urban areas. The "BDS+GPS+GLONASS" combination was adopted for realtime positioning measurement of network RTK, which was centered and leveled with legs and the base. Beibu Gulf System and Guangxi CORS dual constellation system were then connected to the triple constellation receiver of the domestic brand (A) RTK respectively to test the positioning accuracy of network RTK. Each point was tested 3 times with 60 epochs observed each time, at the sampling interval of $1 \mathrm{~s}$; between every two times of observation, the equipment was initialized. The test results were shown in Figure 4 5.

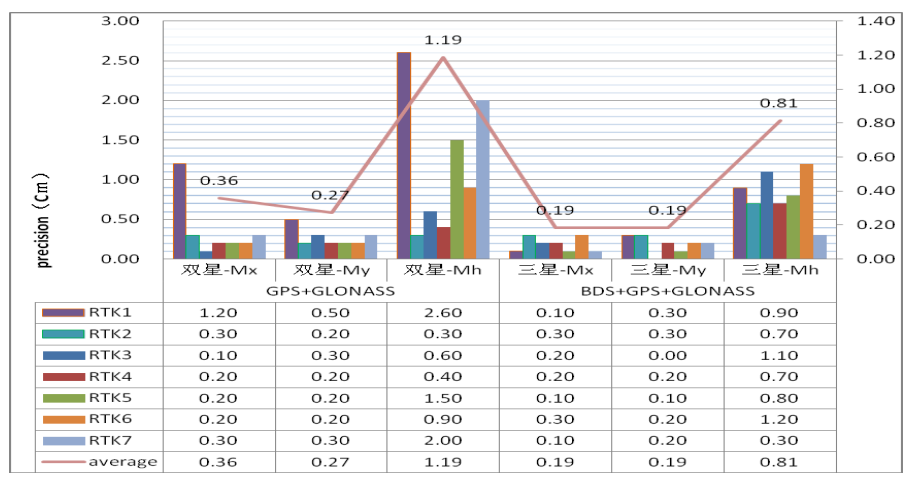

Figure 4. Comparison of the Results of (Internal Accordant) Accuracy of Network RTK Positioning

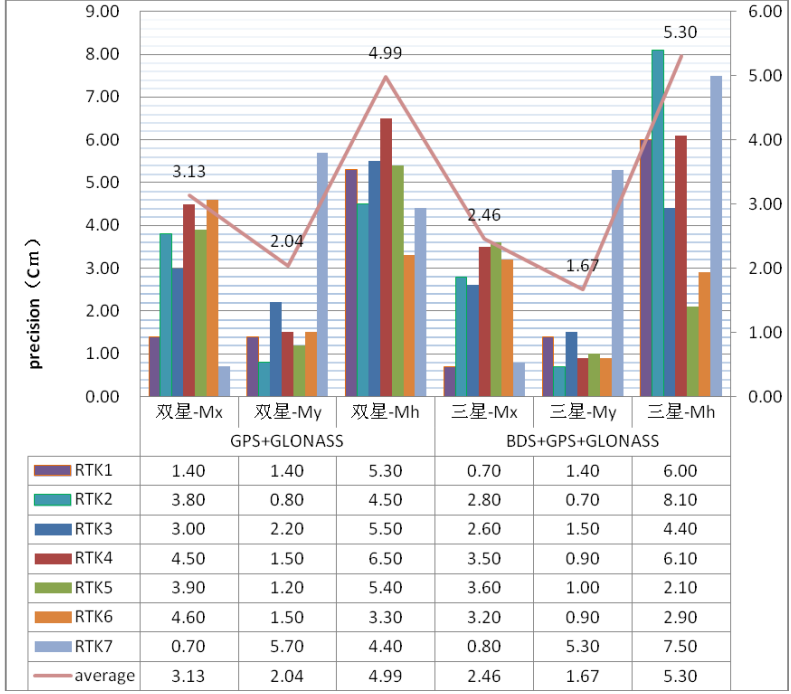

Figure 5. Comparison of the Results of (External Accordant) Accuracy of Network RTK Positioning

From Figure 4 and Figure 5, it was evident that the average internal accordant accuracy of points in Beibu Gulf Beidou System was $\pm 0.27 \mathrm{~cm}$ horizontally and $\pm 0.81 \mathrm{~cm}$ vertically; that of Guangxi CORS dual constellation system in Beibu Gulf was $\pm 0.45 \mathrm{~cm}$ horizontally and $\pm 1.19 \mathrm{~cm}$ vertically, $40 \%$ and $31.9 \%$ higher compared with the dual constellation system in the horizontal and vertical directions respectively. The average external accordant accuracy of points in Beibu Gulf Beidou System was $\pm 2.97 \mathrm{~cm}$ horizontally and $\pm 5.30 \mathrm{~cm}$ vertically; that of Guangxi CORS dual constellation system in Beibu Gulf was $\pm 3.74 \mathrm{~cm}$ horizontally and $\pm 4.99 \mathrm{~cm}$ vertically, $20.6 \%$ higher compared with the dual constellation system in the horizontal direction (equivalent in the vertical direction).

\section{Conclusion}

According to test results, Beibu Gulf triple constellation high-precision reference station network reached the networkwide time availability of $92.7 \%$ within effective coverage, $1 \%$ higher in average effective time availability compared with the dual constellation system; the percentage of fixed solutions to spatial accessibility was about $87.3 \%$; the average internal accordant accuracy of network RTK positioning was $37.7 \%$ and $33.3 \%$ higher than the dual constellation system in the horizontal and vertical directions respectively; the average external accordant accuracy was $20.60 \%$ higher in the horizontal direction and equivalent in the vertical direction compared with the dual constellation system; on the whole, its navigation and positioning effects were better than the dual constellation system and could meet the requirements of highprecision positioning.

\section{References}

[1] References from Books: Whitepaper on Beidou Navigation Satellite System of China. State Council Information Office of the People's Republic of China, June 16, 2016

[2] References from Journals: Xinying Zhong,Rijuan Huang,Tang Dan,Changzeng Tang. The research of the current situation ablut the Compass Ground-based Augmentation System. International Conference on Intelligent Earth Observing and Applications 2015(EI) 
[3] References from Journals: Yang Ailing, Zhou Quan, Zhang Xiaolei. Analysis and Reflections on the Construction of Beidou CORS Network. Geomatics \& Spatial Information Technology, 2015, 38 (10): 61-63

[4] References from Journals: Zhang Guoping. Reflections on Construction of the Changjiang Trunk Beidou CORS. Bulletin of Surveying and Mapping, 2015 (7): 5-8

[5] References from Journals: Tang Wenjie, Lv Zhiwei, Wang Binghao, Shi Xin, Yu Xiaodong. Analysis of Positioning Precision of Network RTK based on BDS CORS. Proceedings of the 6th China Satellite Navigation Conference--S01 Application of Beidou/GNSS Navigation. 2015 (5) 